\title{
Examining guidelines and new evidence in oncology nutrition: a position paper on gaps and opportunities in multimodal approaches to improve patient care
}

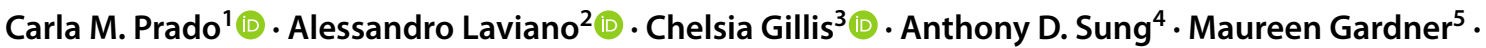 \\ Suayib Yalcin ${ }^{6}\left(\mathbb{D}^{\circ}\right.$. Suzanne Dixon ${ }^{7}(\mathbb{D})$. Shila M. Newman ${ }^{8} \cdot$ Michael D. Bastasch $^{9} \cdot$ Abby C. Sauer $^{10}$. \\ Refaat Hegazi ${ }^{10}$ (D) Martin R. Chasen ${ }^{11,12,13}$
}

Received: 1 July 2021 / Accepted: 27 October 2021 / Published online: 23 November 2021

(c) The Author(s) 2021

\begin{abstract}
Malnutrition, muscle loss, and cachexia are prevalent in cancer and remain key challenges in oncology today. These conditions are frequently underrecognized and undertreated and have devastating consequences for patients. Early nutrition screening/assessment and intervention are associated with improved patient outcomes. As a multifaceted disease, cancer requires multimodal care that integrates supportive interventions, specifically nutrition and exercise, to improve nutrient intake, muscle mass, physical functioning, quality of life, and treatment outcomes. An integrated team of healthcare providers that incorporates societies' recommendations into clinical practice can help achieve the best possible outcomes. A multidisciplinary panel of experts in oncology, nutrition, exercise, and medicine participated in a 2-day virtual roundtable in October 2020 to discuss gaps and opportunities in oncology nutrition, alone and in combination with exercise, relative to current evidence and international societies' recommendations. The panel recommended five principles to optimize clinical oncology practice: (1) position oncology nutrition at the center of multidisciplinary care; (2) partner with colleagues and administrators to integrate a nutrition care process into the multidisciplinary cancer care approach; (3) screen all patients for malnutrition risk at diagnosis and regularly throughout treatment; (4) combine exercise and nutrition interventions before (e.g., prehabilitation), during, and after treatment as oncology standard of care to optimize nutrition status and muscle mass; and (5) incorporate a patient-centered approach into multidisciplinary care.
\end{abstract}

Keywords Malnutrition $\cdot$ Low muscle mass $\cdot$ Nutrition $\cdot$ Exercise $\cdot$ Multimodal $\cdot$ Multidisciplinary

Martin R. Chasen

Martin.Chasen@williamoslerhs.ca

1 Human Nutrition Research Unit, Department of Agricultural, Food and Nutritional Science, University of Alberta, Edmonton, AB, Canada

2 Department of Translation and Precision Medicine, Sapienza University of Rome, Rome, Italy

3 Peri Operative Program, McGill University Health Center, Montreal, QC, Canada

4 Department of Medicine, Division of Hematologic Malignancies and Cellular Therapy, Duke University School of Medicine, Durham, NC, USA

5 Florida Cancer Specialists and Research Institute, Fort Myers, FL, USA
6 Department of Medical Oncology, Hacettepe University Cancer Institute, Sihhiye, Ankara, Turkey

7 Humana Healthcare Research, Portland, OR, USA

8 Thompson Cancer Survival Center, Knoxville, TN, USA

9 University of Texas Health/East Texas Cancer Institute, Athens, TX, USA

10 Scientific \& Medical Affairs, Abbott Nutrition, Columbus, $\mathrm{OH}, \mathrm{USA}$

11 Department of Medicine, University of Toronto, Toronto, Canada

12 William Osler Health System, Brampton, ON, Canada

13 Department of Family Medicine, McMaster University, Hamilton, ON, Canada 


\section{Introduction}

Malnutrition, muscle loss, and cachexia are prevalent in patients with cancer and associated with poor outcomes, regardless of body weight or body mass index (BMI). Approximately $70 \%$ of patients with cancer develop malnutrition [1]. Low muscle mass is a phenotypic criterion of malnutrition affecting approximately $40 \%$ of patients and may be caused by reduced intake, low levels of physical activity, effects of cancer, and/or anticancer therapies [2,3]. Low muscle mass also occurs in cachexia (with or without loss of fat mass), a multifactorial wasting syndrome occurring in 50 to $80 \%$ of patients [4]. These conditions can occur before diagnosis, as well as during or after treatment [3, 5]. If untreated, they are associated with reduced physical function and quality of life, dose-limiting toxicities, reduced treatment response, increased risks for surgical complications, and reduced survival [3, 6-10]. In addition, they strain healthcare and economic resources, extending hospital length of stay (LOS) and increasing risks for unplanned hospitalizations and readmissions $[10,11]$.

Ensuring access to nutrition resources is fundamental to quality care. Early and proactive nutrition care - consisting of screening, assessment, and intervention - is associated with improved outcomes as patients progress through their cancer journey to cure or palliation [12-15]. A multidisciplinary team (MDT) approach to nutrition care is associated with mitigating the sequelae of malnutrition, muscle loss, and cachexia and improving outcomes [16].

A panel of international multidisciplinary experts in oncology and nutrition, exercise, and internal and family medicine participated in a virtual scientific roundtable in October 2020 to discuss gaps and opportunities in oncology nutrition care relative to international societies' recommendations and current scientific evidence. The goals of this position paper are to (1) raise awareness around the lack of access to comprehensive nutrition care as an obstacle to optimizing patient outcomes, (2) increase understanding that nutrition interventions alone and in the context of multimodal care and delivered using MDT approaches increase the efficacy of anticancer therapies to improve outcomes, (3) highlight new evidence relative to current guideline categories of screening, assessment, intervention, and monitoring, and (4) provide clinical practice principles to optimize nutrition care in oncology.

\section{The combined burden of malnutrition and low muscle mass in cancer}

Malnutrition (undernutrition) can result from inadequate intake and/or uptake of nutrients that can cause muscle mass loss, leading to reduced physical function and impaired clinical outcomes [17]. The prevalence of malnutrition is higher and more severe among older patients and those with upper gastrointestinal (GI), head and neck, and lung cancers than among patients with other cancer types [18]. The burden of malnutrition can be compounded by co-occurring low muscle mass in patients who are underor overweight. More than $50 \%$ of newly diagnosed cancers are in patients with BMIs $\geq 25.0 \mathrm{~kg} / \mathrm{m}^{2}$, among whom more than $60 \%$ can be at nutritional risk or malnourished $[2,19]$.

Low muscle mass (also referred to as sarcopenia) is a central feature of cancer. Sarcopenia in cancer is often secondary (disease-related), not primary (age-related), though the presence of age-related cachexia can be exacerbated by a cancer diagnosis [20]. Secondary sarcopenia has predominantly focused on muscle mass loss without consideration of muscle function, and the terms low muscle mass or myopenia may be used to avoid confusion with primary sarcopenia's diagnostic criteria [21, 22]. Although malnourished patients can have low muscle mass, malnutrition may be present without myopenia or sarcopenia.

In addition to locating tumors to assess treatment response, computed tomography (CT) can be used to detect low muscle mass and the degree of fatty infiltration in muscle (myosteatosis). The relationship between low muscle mass and outcomes in patients with cancer is well documented [10, 23, 24]. A pooled analysis of skeletal muscle mass in patients with colorectal cancer $(n=215)$ found that low muscle mass was an independent predictor of poor treatment response and progression-free survival [23]. Similarly, a meta-analysis of 70 studies of patients with GI tumors $(n=21875)$ demonstrated that preoperative low muscle mass was associated with increased risks for surgical complications and mortality [24]. Myosteatosis is an indicator of muscle quality and a predictor of poor patient outcomes [10, 25]. An analysis of 1630 preoperative patients with stages I to III colon cancer found increased hospital LOS, mortality rate, and postoperative complication risk among individuals with low muscle mass and/or myosteatosis compared with patients with adequate muscle mass and quality [10]. Notably, ultrasound is an additional tool that can measure muscle mass and quality (by echogenicity); however, its use in oncology has not been fully explored.

Many patients develop cachexia (also referred to as cancer-associated malnutrition), a wasting syndrome that cannot be fully reversed by conventional nutrition interventions (i.e., additional protein and energy). It is characterized by anorexia and systemic inflammation, which create negative protein and energy balance, leading to weight loss (with or without fat loss) and muscle wasting [26]. Cachexia can worsen with anticancer treatment and has 
severe negative consequences on quality and length of life [26]. Additionally, it can be present in patients with excess weight and is frequently underrecognized in this population [27]. Among 1473 patients with GI or respiratory tract cancers, Cox proportional hazard modeling demonstrated the combination of weight loss and low muscle mass and quality was associated with reduced survival across BMI categories. [27]. Interestingly, weight stability may mask changes in muscle quantity and quality. In a large sample of patients with early stage colorectal cancer $(n=1026)$, Brown et al. showed that despite weight stability, one in eight patients developed low muscle mass and one in seven developed myosteatosis during a 15-month followup period [28].

\section{Nutrition care practice: recommendations and current evidence}

The goals of nutrition therapy are to maintain or improve energy and protein intake, mitigate metabolic abnormalities, preserve physical function, reduce the risk of treatment intolerance, and improve quality of life before, during, and after curative or palliative treatment [29]. The nutrition care process is a systematic way of providing nutrition care to patients across healthcare settings and is used to address these goals, which is an important aim of the MDT care approach (Fig. 1) [30].
Not all patients have access to comprehensive nutrition care, in particular when dietitian staffing is insufficient, reimbursement for nutrition services is absent, or screening standards are lacking. In a survey of cancer survivors ( $n=1073$ responses), fewer than $40 \%$ of patients with involuntary weight loss reported being seen by a dietitian during treatment [31]. Trujillo et al. reported that the average dietitian-to-patient ratio in outpatient cancer centers in the USA was 1:2308, far below the estimated ratio of 1:120 needed to provide proactive nutrition care and highlighting the need to expand nutrition resources and improve reimbursement [32].

Many international nutrition societies recognize the importance of nutrition as essential to comprehensive, high-quality oncology care. Societies, including the American Society of Clinical Oncology (ASCO), the American Society of Parenteral and Enteral Nutrition (ASPEN), the European Society for Clinical Nutrition and Metabolism (ESPEN), have published recommendations regarding nutrition care to guide clinical practice and improve patient and healthcare outcomes (Table 1).

\section{Screening for malnutrition risk and low muscle mass}

All clinical nutrition societies and several oncology societies recommend screening for malnutrition risk at diagnosis and during and after treatment (Supplementary Table 1). Several validated screening tools are available, such as the
Fig. 1 Proposed nutrition care process for oncology. $*$ MST $=$ Malnutrition Screening Tool; EHR/EMR $=$ Electronic Health Record/Electronic Medical Record; SGA = Subjective Global Assessment

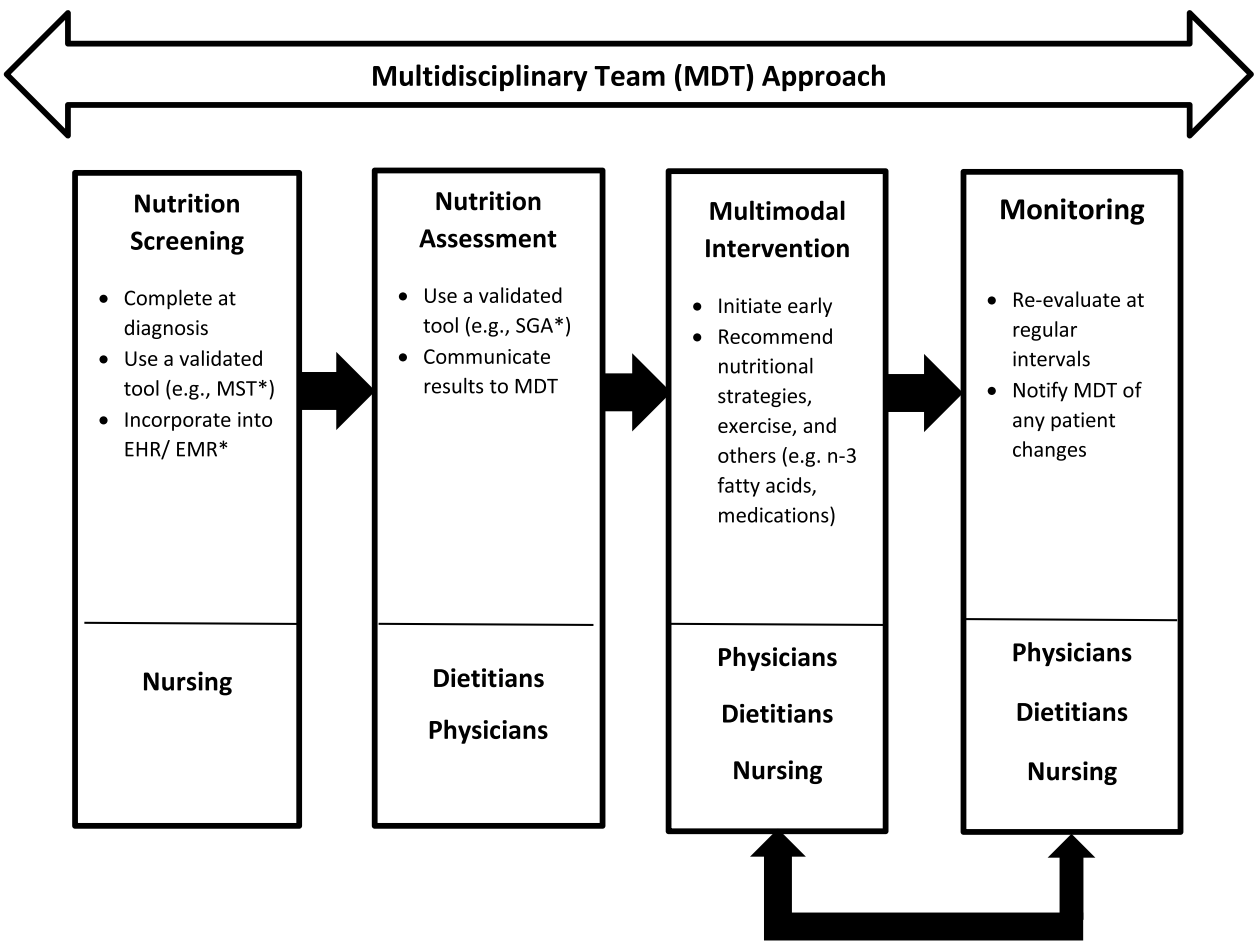


Table.1 Nutrition care process - expert organization recommendations

\begin{tabular}{|c|c|c|c|c|c|c|c|}
\hline Expert society & $\begin{array}{l}\text { Malnutri- } \\
\text { tion screen- } \\
\text { ing }\end{array}$ & $\begin{array}{l}\text { Nutrition } \\
\text { assess- } \\
\text { ment }\end{array}$ & $\begin{array}{l}\text { Nutrition } \\
\text { interven- } \\
\text { tion }\end{array}$ & Exercise & $\begin{array}{l}\text { Multimodal } \\
\text { intervention }\end{array}$ & Monitoring & $\begin{array}{l}\text { Multidis- } \\
\text { ciplinary } \\
\text { team }\end{array}$ \\
\hline \multicolumn{8}{|l|}{ Nutrition } \\
\hline Academy of Nutrition and Dietetics (AND) & $\mathrm{X}$ & $\mathrm{X}$ & $\mathrm{X}$ & & & $\mathrm{X}$ & $\mathrm{X}$ \\
\hline $\begin{array}{l}\text { American Society for Parenteral and Enteral Nutrition } \\
\text { (ASPEN) }\end{array}$ & $\mathrm{X}$ & $\mathrm{X}$ & $\mathrm{X}$ & & & & \\
\hline $\begin{array}{l}\text { European Society for Clinical Nutrition and Metabo- } \\
\text { lism (ESPEN) }\end{array}$ & $\mathrm{X}$ & $\mathrm{X}$ & $\mathrm{X}$ & $\mathrm{X}$ & $\mathrm{X}$ & & \\
\hline $\begin{array}{l}\text { Italian Society of Medical Oncology (AIOM) \& Ital- } \\
\text { ian Society of Artificial Nutrition and Metabolism } \\
\text { (SINPE) }\end{array}$ & $\mathrm{X}$ & $\mathrm{X}$ & $\mathrm{X}$ & & & $\mathrm{X}$ & $\mathrm{X}$ \\
\hline \multicolumn{8}{|l|}{ Oncology/medicine } \\
\hline American College of Surgeons (ACS)* & $\mathrm{X}$ & $\mathrm{X}$ & $\mathrm{X}$ & & & & $\mathrm{X}$ \\
\hline American Society of Clinical Oncology (ASCO) & $\mathrm{X}$ & $\mathrm{X}$ & $\mathrm{X}$ & & & & \\
\hline Association of Community Cancer Centers (ACCC) & $\mathrm{X}$ & & $\mathrm{X}$ & & & $\mathrm{X}$ & $\mathrm{X}$ \\
\hline Clinical Oncology Society of Australia (COSA) & $\mathrm{X}$ & $\mathrm{X}$ & $\mathrm{X}$ & $\mathrm{X}$ & & & $\mathrm{X}$ \\
\hline European Society for Medical Oncology (ESMO) & $\mathrm{X}$ & & $\mathrm{X}$ & $\mathrm{X}$ & $\mathrm{X}$ & $\mathrm{X}$ & \\
\hline National Comprehensive Cancer Network (NCCN) & $\mathrm{X}$ & $\mathrm{X}$ & $\mathrm{X}$ & & & $\mathrm{X}$ & $\mathrm{X}$ \\
\hline Gastroenterological Society of Taiwan & & $\mathrm{X}$ & $X$ & & & & \\
\hline $\begin{array}{l}\text { United Kingdom National Multidisciplinary Guidelines } \\
\text { Exercise }\end{array}$ & $\mathrm{X}$ & $X$ & $\mathrm{X}$ & $\mathrm{X}$ & $X$ & $\mathrm{X}$ & $\mathrm{X}$ \\
\hline American College of Sports Medicine (ACSM) & & & & $\mathrm{X}$ & & & \\
\hline $\begin{array}{l}\text { Exercise for People with Cancer Guideline Develop- } \\
\text { ment (Cancer Care Ontario's Program in Evidence- } \\
\text { Based Care) }\end{array}$ & & & & $X$ & & & \\
\hline
\end{tabular}

*From Optimal Resources for Cancer Care, 2020 Standards; These standards are intended solely as qualification criteria for Commission on Cancer $(\mathrm{CoC})$ accreditation. They do not constitute a standard of care and are not intended to replace the medical judgment of the physician or healthcare professional in individual circumstances

Malnutrition Screening Tool (MST), which can be administered quickly by nursing staff [33].

Screening is not mandated in most countries, nor is it standardized. Trujillo et al. reported that $53 \%$ of outpatient cancer centers in the USA screened for malnutrition risk and $65 \%$ used a validated screening tool [32]. A quality assurance performance improvement program, implemented in outpatient cancer treatment centers to assess the feasibility of standardizing malnutrition screening with a validated tool embedded in the electronic health record/electronic medical record (EHR/EMR), found that the rate of screening increased from $60 \%$ at baseline to $78 \%$ at 20 months [34].

Because muscle loss is common, the Clinical Oncology Society of Australia recommends all patients be screened for low muscle mass at diagnosis and re-screened when patients' clinical situations change, using the SARC-F questionnaire alone or in combination with calf circumference (SARC-CalF) [35]. However, these tools have not been fully explored and validated in patients with cancer. SARC-F is a geriatric assessment related to functional outcomes and has not yet been proven to be ideal for use in patients with cancer of all ages, but may have acceptable performance among older patients with cancer [36, 37]. In the aging literature, although SARC-F performs satisfactorily for evaluating muscle function, SARC-CalF has greater screening efficacy than SARC-F for identifying low muscle function and low muscle mass in older adults $[38,39]$. Importantly, adjustment factors for the confounding effects of adiposity on calf circumference have been recently published (Table 2) [40]. This study was conducted in a healthy adult population and appears to be the only feasible means to identify low calf circumference in patients with excess weight; its use in clinical practice is yet to be explored [40]. Additional data are needed to fully characterize the screening performance of SARC-CalF in oncology.

\section{Nutrition assessment to diagnose malnutrition}

Nutrition assessment can be conducted using several available tools to evaluate nutrition status, such as the Subjective Global Assessment (SGA) and the Patient-Generated Subjective Global Assessment (PG-SGA) [41, 42]. Nutrition 
Table.2 BMI adjustment factors for calf circumference outside BMI range of $18.5-24.9 \mathrm{~kg} / \mathrm{m}^{2}$ by ethnicity/race ( adapted from Gonzalez 2021)

\begin{tabular}{|c|c|c|c|c|c|c|c|c|}
\hline & \multicolumn{4}{|c|}{ BMI category - males $(\mathrm{cm})$} & \multicolumn{4}{|c|}{ BMI category - females $(\mathrm{cm})$} \\
\hline & $<18.5$ & $25-29.9$ & $30-39.9$ & $\geq 40$ & $<18.5$ & $25-29.9$ & $30-39.9$ & $\geq 40$ \\
\hline Non-Hispanic White & +5.0 & -3.0 & -7.0 & -12.0 & +4.0 & -3.0 & -7.0 & -12.0 \\
\hline Non-Hispanic Black & +4.0 & -3.0 & -7.0 & -12.0 & +4.0 & -3.0 & -7.0 & -12.0 \\
\hline Mexican American & +4.0 & -3.0 & -6.0 & -12.0 & +4.0 & -3.0 & -6.0 & -12.0 \\
\hline Other & +3.0 & -4.0 & -7.0 & -12.0 & +4.0 & -3.0 & -7.0 & -11.0 \\
\hline
\end{tabular}

assessment is different from nutrition screening in that it determines the presence, severity, and causes of malnutrition and is used to plan nutrition intervention, while screening indicates the presence or absence of malnutrition risk. [43].

Nutrition societies recommend early nutrition assessment for all at-risk patients before anticancer treatments (including surgery) begin, with reassessments at regular intervals throughout the cancer trajectory (Supplementary Table 2). ESPEN also recommends dual X-ray absorptiometry, anthropometry, bioelectrical impedance analysis, or CT scans to assess muscle mass, and walking tests or dynamometers (i.e., hand-grip strength) for muscle function [29].

With the lack of consensus on the diagnostic criteria for malnutrition, a framework such as the one proposed by the Global Leadership Initiative on Malnutrition (GLIM) can be used to help diagnose malnutrition through (1) identifying at-risk patients using any validated screening tool and (2) conducting a nutrition assessment using validated assessment tools to diagnose and grade the severity of malnutrition. GLIM's diagnostic criteria include three phenotypic criteria (involuntary weight loss, low BMI, and reduced muscle mass) and two etiologic criteria (reduced food intake or assimilation and inflammation or disease burden) [44].

\section{Interventions}

\section{Nutrition therapy is essential in cancer care}

Nutrition intervention encompasses nutrition counseling and education, oral nutritional supplements (ONS), and enteral and/or parenteral nutrition support, as appropriate for each individual case. Healthcare providers should proactively identify early indicators of malnutrition risk in their patients (e.g., anorexia and reduced food intake) and intervene with additional protein and energy before cachexia develops, rather than reactively doing so when patients become severely depleted (i.e., refractory cachexia). Intervening early and throughout treatment may help to improve nutrition status and, ultimately, quality and length of life [45]. Nutrition societies recommend intervening early to support an adequate intake during and after treatment that is based on a patient's total energy and protein needs (Supplementary Table 3 and Fig. 2), disease status, current intake, lifestyle, and food preferences. Several

\section{Energy: $\quad 25-30 \mathrm{kcal} / \mathrm{kg} /$ day Protein: $\quad$ 1-1.5 g protein $/ \mathrm{kg} /$ day}

Fig. 2 Expert energy and protein recommendations for patients with cancer

RCTs, systematic reviews, and meta-analyses involving patients with different tumor types and undergoing various anticancer treatments have shown that nutrition therapy improves weight status, energy and protein intakes, treatment tolerance, and survival and reduces nutrition impact symptoms, hospital readmissions, and mortality [12-15, 46]. While not all evidence supporting oncology nutrition is based on RCTs, the body of evidence is substantial and should not be dismissed. This is an important consideration given the frequency of non-evidence-based medical practice in oncology, which has been reported to occur in $33 \%$ of patients [47].

Specific nutrients may have important roles in improving nutrition status while mitigating metabolic changes and the consequential decline in muscle mass and physical function in patients with cancer. One example is eicosapentaenoic acid (EPA), a long-chain omega-3 fatty acid $(\omega-3)$ found in fish oil, with some current guidelines recommending EPA or fish oil supplementation to stabilize or improve appetite, and increase food intake, muscle mass, and body weight in patients with cachexia and/or advanced cancer who are undergoing chemotherapy [29, 48]. A systematic review and meta-analysis of 11 RCTs $(n=1350)$ demonstrated consuming high-protein ONS enriched with $\omega-3$ fatty acids was associated with improved body weight, attenuated lean mass loss, and improved selected domains of quality of life among patients receiving chemotherapy [49].

\section{Exercise is important in cancer care}

Aerobic and resistance exercise during anticancer treatments preserves or improves aerobic capacity, muscle mass and strength, and quality of life $[50,51]$. Several societies 
advocate regular exercise before, during, and after treatment as a standard of care in oncology (Supplementary Table 4). Exercise is safe and well-tolerated by most patients with various cancer types [52]. However, patients who have had lung or abdominal surgeries or have ostomies, ataxia, extreme fatigue, severe malnutrition, or bone metastases need to be under the care of physical and occupational therapists, or physical medicine and rehabilitation physicians (in conjunction with the dietitian), and should only undertake the physical activity with their guidance and supervision [52]. Exercise recommendations for most patients with cancer and healthy adults (Fig. 3) are similar, although care must be taken to support the additional energy needs of patients with malnutrition who engage in exercise $[53,54]$.

Prehabilitation exercise is a structured intervention implemented before surgery, which has been found to be safe, and is often delivered as a combination of moderate, continuous cardiovascular activity in combination with resistance training or high-intensity interval training, with the aim of improving functional capacity and increasing muscle mass pre-surgery or pre-treatment (e.g., within 4 to 6 weeks). Both unimodal (exercise only) and multimodal prehabilitation (exercise with nutrition) programs can facilitate recovery and reduce postoperative complications [55].

\section{Multidisciplinary teams provide multimodal treatment}

Multidisciplinary teams are dedicated to developing and providing multimodal, patient-centered care throughout the cancer journey (Fig. 1 and Supplementary Table 5). In a pilot trial $(n=34)$ integrating a patient-centered, bestpractice (i.e., evidence-based) head and neck cancer care model with an MDT approach, malnutrition screening increased from 14 to $88 \%$, and early access to dietitians from 20 to $97 \%$, while unplanned hospital admissions and costs were reduced, and communication and care coordination improved [16]. Of note, oncology nurse navigators, who practice mainly in the USA, can play an important role in the MDT by working closely with patients to ensure improved access to supportive care resources and optimal patient comprehension of the diagnosis and cancer treatment options.

Multimodal therapy is the combination of two or more interventions designed to improve specific outcomes

\begin{tabular}{|ll|}
\hline Moderate-to-vigorous activity: & 150 minutes per week \\
Strength training: & At least twice a week \\
\hline
\end{tabular}

Fig. 3 Expert recommendations on type and amount of exercise per week for patients with cancer
(Supplementary Table 6). Despite the lack of standards to treat cachexia, evidence indicates multimodal therapy including nutrition counseling and ONS to promote protein and energy balance, EPA supplementation and nonsteroidal anti-inflammatory drugs to reduce inflammation, and moderate resistance exercise to increase anabolism [56-58] will improve outcomes. Current evidence suggests that this type of multimodal intervention is feasible, safe, and associated with improvements in weight and nutrition status, physical performance, and symptom severity and may be beneficial to patients with cachexia and advanced cancers [15, 59]. The Multimodal Intervention Exercise, Nutrition and Inflammatory Medication (MENAC) is an ongoing, international RCT evaluating the effect of an early and sustained multimodal program on changes in body weight, muscle mass, and physical activity in patients newly diagnosed with lung or pancreatic cancer and starting cancer treatment $(n=240)$ [60].

Another multimodal approach implements a prehabilitation intervention that combines (1) personalized nutrition counseling and supplementation as needed, (2) individualized aerobic and weight resistance exercises, and (3) anxiety reduction and relaxation strategies to prepare patients for the anticipated detrimental effects of surgery. The majority of research has been conducted in surgery patients (94\%), with several RCTs showing prehabilitation incorporating these three components facilitated earlier return to pre-surgery physical function levels and was associated with greater gains in muscle mass (compared to rehabilitation), and reduced hospital LOS and healthcare costs [61-65].

\section{Monitoring occurs throughout a patient's journey}

Nutrition monitoring should begin at diagnosis and continue throughout the cancer trajectory. It involves evaluating patients' response to nutrition and exercise interventions, regularly reassessing nutrition status, and providing followup care to support recovery from the detrimental effects of treatment on body composition, physical function, and quality of life (Supplementary Table 7). Along with proactive nutrition and exercise interventions during cancer treatment, continuous monitoring and intervening after treatment can facilitate recovery from anticancer treatments and surgery and improve nutrition status, muscle mass, and physical function. Ensuring the continuity and monitoring of nutrition care is essential, including the transition from hospital to home [66]. 
Fig. 4 Clinical practice principles for the nutrition care of patients with cancer

Principle 1: Position oncology nutrition at the center of multidisciplinary care.

- Malnutrition and muscle loss can lead to poor outcomes. Nutrition interventions are associated with improving quality of life, nutrient intake, muscle mass, and physical performance and tolerance to anticancer treatments.

Principle 2: Partner with colleagues and administrators to integrate a nutrition care process into the multidisciplinary cancer care approach.

- Nutrition care is a multidisciplinary endeavor, with each member contributing to the process. Delivering nutrition care within the MDT improves healthcare outcomes and enhances communication and coordination of patient-centered care.

Principle 3: Screen all patients for malnutrition risk at diagnosis and regularly throughout treatment.

- Use validated tools like the MST. Create systems that make screening easy and quick. Initiate systematic referrals of at-risk patients to dietitians for assessment and intervention.

- Recognize that validated tools to screen for muscle loss are needed.

Principle 4: Combine exercise and nutrition interventions before (e.g., prehabilitation), during, and after treatment as oncology standard of care to optimize nutrition status and muscle mass.

- Cancer treatment requires multimodal interventions in the context of the MDT. Societies recommend multimodal interventions that include both nutrition and exercise to both manage cachexia and to prepare patients for surgery.

Principle 5: Incorporate a patient-centered approach into multidisciplinary care.

- Provide quality nutrition care to ensure patients with cancer receive the right nutrition care at the right time and at the right place in line with the patient's self-directed care goals.

\section{Position of the experts on nutrition care for patients with cancer}

Recognizing the challenges of caring for patients with cancer, and optimizing patient outcomes with nutrition and exercise interventions, this expert panel recommends combining societies' recommendations and current evidence to implement the following principles to guide clinical practice (Fig. 4):

\section{Position oncology nutrition at the center of multidisci- plinary care}

Ample evidence supports that adequately nourished patients benefit from anticancer treatments and supportive interventions, which lessens the challenges of medical management of this population. One path to positioning oncology nutrition as a standard of care is to ensure that MDT members are educated and trained to screen, evaluate, and monitor at-risk and malnourished patients with cancer and understand how and when to refer to a registered dietitian for more in-depth nutrition care. Most healthcare providers do not receive clinical nutrition education, and it may be low on the list of competing clinical priorities. Some societies, such as ASPEN and ESPEN, provide funding for nutrition fellowships for physicians. Perhaps extending similar educational and training opportunities to nurses would help to elevate the value and importance of oncology nutrition as standard practice within MDTs.

2. Partner with colleagues and administrators to integrate a nutrition care process into the multidisciplinary cancer care approach.

In most oncology clinics, nutrition care is usually the domain of dietitians and is managed in isolation. Delivering effective nutrition care is possible when MDT members coordinate and communicate nutrition care 
(Fig. 1). In addition, patients often receive conflicting information and advice about nutrition from healthcare providers; therefore, all members of the MDT need to be knowledgeable about oncology nutrition so they can provide patients with consistent and accurate nutrition guidance.

3. Screen all patients for malnutrition risk at diagnosis and regularly throughout treatment

Nursing-led screening for malnutrition at diagnosis is essential. Organizational processes to standardize screening are recommended, where positive results are documented and communicated to the MDT and patients are referred to a dietitian, as appropriate, for further assessment and follow-up.

Although evidence indicates a high percentage of patients with newly diagnosed cancer have low muscle mass, no validated tools to screen for muscle loss currently exist, representing knowledge gaps researchers and expert societies need to address.

4. Combine exercise and nutrition interventions before (e.g., prehabilitation), during, and after treatment as oncology standard of care in oncology to optimize nutrition status and muscle mass

Cancer is a multifaceted disease requiring multimodal interventions best delivered by MDTs. Current guidelines recommend exercise combined with nutrition interventions as a standard of care. Combining these supportive interventions is associated with improving patients' quality of life and health-related outcomes in cachexia. Perioperative multimodal interventions, such as prehabilitation, can improve physical function, increase muscle mass, and reduce complications among patients undergoing surgery.

5. Incorporate patient-centered approaches into multidisciplinary care

In patient-centered, collaborative, and coordinated care, a patient's health needs and desired health outcomes guide decisions regarding their healthcare. The key components of patient-centered care include patient education and empowerment, patient-centered communication, coordinated and integrated care, and provision of emotional support [67].

\section{Conclusion/relevance}

Malnutrition, muscle loss, and cachexia in cancer impact patient and healthcare outcomes. Using multimodal supportive interventions that include nutrition and exercise are associated with preventing and treating these comorbidities and improving outcomes. Delivering this level of care is achievable when societies' recommendations become part of standard clinical practice and an MDT is involved. Early and systematic screening for malnutrition risk using validated tools and EHR/EMR technology when available is quick, feasible, and sustainable, with at-risk patients promptly referred to dietitians for assessment and intervention. The MDT approach to nutrition care in oncology is associated with improved screening, assessment, access to comprehensive care and enhances communication and collaboration within the MDT, thus improving patient care overall. Patient-centered nutrition care is at the core of MDT and is an important strategy to improve nutrition status and maintain quality of life for all patients with cancer.

Supplementary Information The online version contains supplementary material available at https://doi.org/10.1007/s00520-021-06661-4.

Acknowledgements The authors thank Carolyn Alish, RD, PhD, of Sterling Medical Communications, LLC, for providing medical writing support, which was funded by Abbott Nutrition.

Author contribution All authors contributed to the concept and content of the manuscript, reviewed and revised it critically, and approved the version to be submitted for publication.

Data availability N/A.

Code availability N/A.

\section{Declarations}

\section{Ethics approval N/A}

Consent to participate N/A

Consent for publication N/A

Conflict of interest CMP reports receiving honoraria and/or paid consultancy from Abbott Nutrition, Nutricia, Nestlé Health Science, Fresenius Kabi, and Baxter. AL reports receiving honoraria and/or paid consultancy from Abbott Nutrition, Baxter, DSM, Fresenius Kabi, Nestlé Health Science, Nutrition, and Smartfish. CG reports honoraria from Abbott Nutrition and Nestlé. ADS reports receiving funding from the NIH and honoraria from Abbott Nutrition. MG, SD, and SMN report receiving honoraria from Abbott Nutrition. ACS and RH are employees of Abbott Nutrition, Abbott Laboratories. The material presented in this article is based on the best-known clinical evidence and is not affected by this financial relationship.

Open Access This article is licensed under a Creative Commons Attribution 4.0 International License, which permits use, sharing, adaptation, distribution and reproduction in any medium or format, as long as you give appropriate credit to the original author(s) and the source, provide a link to the Creative Commons licence, and indicate if changes were made. The images or other third party material in this article are included in the article's Creative Commons licence, unless indicated otherwise in a credit line to the material. If material is not included in the article's Creative Commons licence and your intended use is not permitted by statutory regulation or exceeds the permitted use, you will need to obtain permission directly from the copyright holder. To view a copy of this licence, visit http://creativecommons.org/licenses/by/4.0/. 


\section{References}

1. de Melo Silva FR, de Oliveira MGOA, Souza ASR et al (2015) Factors associated with malnutrition in hospitalized cancer patients: a cross-sectional study. Nutr J 14;123. https://doi.org/ 10.1186/s12937-015-0113-1

2. Ní Bhuachalla ÉB, Daly LE, Power DG et al (2018) Computed tomography diagnosed cachexia and sarcopenia in 725 oncology patients: is nutritional screening capturing hidden malnutrition? J Cachexia Sarcopenia Muscle 9:295-305. https://doi.org/10.1002/ jcsm. 12258

3. Martin L, Gioulbasanis I, Senesse P, Baracos VE (2020) Cancerassociated malnutrition and CT-defined sarcopenia and myosteatosis are endemic in overweight and obese patients. JPEN J Parenter Enteral Nutr 44:227-238. https://doi.org/10.1002/jpen. 1597

4. Argilés JM, Busquets S, Stemmler B, López-Soriano FJ (2014) Cancer cachexia: understanding the molecular basis. Nat Rev Cancer 14:754-762. https://doi.org/10.1038/nrc3829

5. Muscaritoli M, Lucia S, Farcomeni A et al (2017) Prevalence of malnutrition in patients at first medical oncology visit: the PreMiO study. Oncotarget 8:79884-79896. https://doi.org/10.18632/ oncotarget. 20168

6. Martin L, Senesse P, Gioulbasanis I et al (2015) Diagnostic criteria for the classification of cancer-associated weight loss. J Clin Oncol 33:90-99. https://doi.org/10.1200/JCO.2014.56. 1894

7. Polański J, Jankowska-Polańska B, Uchmanowicz I et al (2017) Malnutrition and quality of life in patients with non-small-cell lung cancer. Adv Exp Med Biol 1021:15-26. https://doi.org/10. 1007/5584_2017_23

8. Gallois C, Artru P, Lièvre A et al (2019) Evaluation of two nutritional scores' association with systemic treatment toxicity and survival in metastatic colorectal cancer: an AGEO prospective multicentre study. Eur J Cancer 119:35-43. https://doi.org/10. 1016/j.ejca.2019.07.011

9. Mintziras I, Miligkos M, Wächter S et al (2018) Sarcopenia and sarcopenic obesity are significantly associated with poorer overall survival in patients with pancreatic cancer: systematic review and meta-analysis. Int J Surg 59:19-26. https://doi.org/10.1016/j.ijsu. 2018.09.014

10. Xiao J, Caan BJ, Cespedes Feliciano EM et al (2020) Association of low muscle mass and low muscle radiodensity with morbidity and mortality for colon cancer surgery. JAMA Surg 155:942-949. https://doi.org/10.1001/jamasurg.2020.2497

11. Freijer K, Tan SS, Koopmanschap MA et al (2013) The economic costs of disease related malnutrition. Clin Nutr 32:136-141. https://doi.org/10.1016/j.clnu.2012.06.009

12. Cereda E, Cappello S, Colombo S et al (2018) Nutritional counseling with or without systematic use of oral nutritional supplements in head and neck cancer patients undergoing radiotherapy. Radiother Oncol 126:81-88. https://doi.org/10.1016/j.radonc. 2017.10.015

13. van der Werf A, Langius JAE, Beeker A et al (2020) The effect of nutritional counseling on muscle mass and treatment outcome in patients with metastatic colorectal cancer undergoing chemotherapy: a randomized controlled trial. Clin Nutr 39:3005-3013. https://doi.org/10.1016/j.clnu.2020.01.009

14. Ravasco P, Monteiro-Grillo I, Vidal PM, Camilo ME (2005) Dietary counseling improves patient outcomes: a prospective, randomized, controlled trial in colorectal cancer patients undergoing radiotherapy. J Clin Oncol 23:1431-1438. https://doi.org/10.1200/ JCO.2005.02.054
15. Blackwood HA, Hall CC, Balstad TR et al (2020) A systematic review examining nutrition support interventions in patients with incurable cancer. Support Care Cancer 28:1877-1889. https://doi. org/10.1007/s00520-019-04999-4

16. Findlay M, Rankin NM, Shaw T et al (2020) Best evidence to best practice: implementing an innovative model of nutrition care for patients with head and neck cancer improves outcomes. Nutrients 12. https://doi.org/10.3390/nu12051465

17. Cederholm T, Barazzoni R, Austin P et al (2017) ESPEN guidelines on definitions and terminology of clinical nutrition. Clin Nutr 36:49-64. https://doi.org/10.1016/j.clnu.2016.09.004

18. Marshall KM, Loeliger J, Nolte L et al (2019) Prevalence of malnutrition and impact on clinical outcomes in cancer services: A comparison of two time points. Clin Nutr 38:644-651. https://doi. org/10.1016/j.clnu.2018.04.007

19. Gioulbasanis I, Martin L, Baracos VE et al (2015) Nutritional assessment in overweight and obese patients with metastatic cancer: does it make sense? Ann Oncol 26:217-221. https://doi.org/ 10.1093/annonc/mdu501

20. Cruz-Jentoft AJ, Baeyens JP, Bauer JM et al (2010) Sarcopenia: European consensus on definition and diagnosis: report of the European Working Group on Sarcopenia in Older People. Age Ageing 39:412-423. https://doi.org/10.1093/ageing/afq034

21. Bauer J, Morley JE, Schols AMWJ et al (2019) Sarcopenia: a time for action. An SCWD position paper. J Cachexia Sarcopenia Muscle 10:956-961. https://doi.org/10.1002/jcsm.12483

22. Fearon K, Evans WJ, Anker SD (2011) Myopenia - a new universal term for muscle wasting. J Cachexia Sarcopenia Muscle 2:1-3. https://doi.org/10.1007/s13539-011-0025-7

23. Sasaki S, Oki E, Saeki H et al (2019) Skeletal muscle loss during systemic chemotherapy for colorectal cancer indicates treatment response: a pooled analysis of a multicenter clinical trial (KSCC 1605-A). Int J Clin Oncol 24:1204-1213. https://doi.org/10.1007/ s10147-019-01460-8

24. Su H, Ruan J, Chen T et al (2019) CT-assessed sarcopenia is a predictive factor for both long-term and short-term outcomes in gastrointestinal oncology patients: a systematic review and meta-analysis. Cancer Imaging 19:82. https://doi.org/10.1186/ s40644-019-0270-0

25. Aleixo GFP, Shachar SS, Nyrop KA et al (2020) Myosteatosis and prognosis in cancer: systematic review and meta-analysis. Crit Rev Oncol Hematol 145:102839. https://doi.org/10.1016/j. critrevonc.2019.102839

26. Fearon K, Strasser F, Anker SD et al (2011) Definition and classification of cancer cachexia: an international consensus. Lancet Oncol 12:489-495. https://doi.org/10.1016/S1470-2045(10) 70218-7

27. Martin L, Birdsell L, Macdonald N et al (2013) Cancer cachexia in the age of obesity: skeletal muscle depletion is a powerful prognostic factor, independent of body mass index. J Clin Oncol 31:1539-1547. https://doi.org/10.1200/JCO.2012.45.2722

28. Brown JC, Caan BJ, Cespedes Feliciano EM et al (2021) Weight stability masks changes in body composition in colorectal cancer: a retrospective cohort study. Am J Clin Nutr. https://doi.org/10. 1093/ajen/nqaa440

29. Muscaritoli M, Arends J, Bachmann P et al (2021) ESPEN practical guideline: clinical nutrition in cancer. Clin Nutr. https://doi. org/10.1016/j.clnu.2021.02.005

30. Swan WI, Vivanti A, Hakel-Smith NA et al (2017) Nutrition care process and model update: toward realizing people-centered care and outcomes management. J Acad Nutr Diet 117:2003-2014. https://doi.org/10.1016/j.jand.2017.07.015

31. Sullivan ES, Rice N, Kingston E et al (2020) A national survey of oncology survivors examining nutrition attitudes, problems 
and behaviours, and access to dietetic care throughout the cancer journey. Clin Nutr. https://doi.org/10.1016/j.clnesp.2020.10.023

32. Trujillo EB, Claghorn K, Dixon SW et al (2019) Inadequate nutrition coverage in outpatient cancer centers: results of a national survey. J Oncol 2019:1-8. https://doi.org/10.1155/2019/ 7462940

33. Ferguson M, Capra S, Bauer J, Banks M (1999) Development of a valid and reliable malnutrition screening tool for adult acute hospital patients. Nutrition 15:458-464. https://doi.org/10.1016/ s0899-9007(99)00084-2

34. Trujillo EB, Shapiro AC, Stephens N et al (2021) Monitoring rates of malnutrition risk in outpatient cancer centers utilizing the malnutrition screening tool embedded into the electronic health record. J Acad Nutr Diet 121:925-930. https://doi.org/10.1016/j. jand.2020.11.007

35. Kiss N, Loeliger J, Findlay M et al (2020) Clinical Oncology Society of Australia: position statement on cancer-related malnutrition and sarcopenia. Nutr Diet 77:416-425. https://doi.org/10.1111/ 1747-0080.12631

36. Williams GR, Al-Obaidi M, Dai C et al (2021) SARC-F for screening of sarcopenia among older adults with cancer. Cancer 127:1469-1475. https://doi.org/10.1002/cncr.33395

37. Fu X, Tian Z, Thapa S et al (2020) Comparing SARC-F with SARC-CalF for screening sarcopenia in advanced cancer patients. Clin Nutr 39:3337-3345. https://doi.org/10.1016/j.clnu.2020.02. 020

38. Barbosa-Silva TG, Menezes AMB, Bielemann RM et al (2016) Enhancing SARC-F: improving sarcopenia screening in the clinical practice. J Am Med Dir Assoc 17:1136-1141. https://doi.org/ 10.1016/j.jamda.2016.08.004

39. Mo Y, Dong X, Wang X-H (2020) Screening accuracy of SARC-F combined with calf circumference for sarcopenia in older adults: a diagnostic meta-analysis. J Am Med Dir Assoc 21:288-289. https://doi.org/10.1016/j.jamda.2019.09.002

40. Gonzalez MC, Mehrnezhad A, Razaviarab N et al (2021) Calf circumference: cutoff values from the NHANES 1999-2006. Am J Clin Nutr. https://doi.org/10.1093/ajcn/nqab029

41. Detsky AS, McLaughlin JR, Baker JP et al (1987) What is subjective global assessment of nutritional status? JPEN J Parenter Enteral Nutr 11:8-13. https://doi.org/10.1177/014860718701100108

42. Ottery FD (1996) Definition of standardized nutritional assessment and interventional pathways in oncology. Nutrition 12:S15S19. https://doi.org/10.1016/0899-9007(95)00067-4

43. Charney P (2008) Nutrition screening vs nutrition assessment: how do they differ? Nutr Clin Pract 23:366-372. https://doi.org/ $10.1177 / 0884533608321131$

44. Cederholm T, Jensen GL, Correia MITD et al (2019) GLIM criteria for the diagnosis of malnutrition - a consensus report from the global clinical nutrition community. Clin Nutr 38:1-9. https:// doi.org/10.1016/j.clnu.2018.08.002

45. Roeland EJ, Bohlke K, Baracos VE et al (2020) Management of cancer cachexia: ASCO Guideline. J Clin Oncol 38:2438-2453. https://doi.org/10.1200/JCO.20.00611

46. Gomes F, Baumgartner A, Bounoure L et al (2019) Association of nutritional support with clinical outcomes among medical inpatients who are malnourished or at nutritional risk: an updated systematic review and meta-analysis. JAMA Netw Open 2:e1915138. https://doi.org/10.1001/jamanetworkopen.2019.15138

47. Levêque D (2008) Off-label use of anticancer drugs. Lancet Oncol 9:1102-1107. https://doi.org/10.1016/S1470-2045(08) 70280-8

48. Thompson KL, Elliott L, Fuchs-Tarlovsky V et al (2017) Oncology evidence-based nutrition practice guideline for adults. J Acad Nutr Diet 117:297-310.e47. https://doi.org/10.1016/j.jand.2016. 05.010
49. de van der Schueren MAE, Laviano A, Blanchard H et al (2018) Systematic review and meta-analysis of the evidence for oral nutritional intervention on nutritional and clinical outcomes during chemo(radio)therapy: current evidence and guidance for design of future trials. Ann Oncol 29:1141-1153. https://doi.org/ 10.1093/annonc/mdy114

50. Fong DYT, Ho JWC, Hui BPH et al (2012) Physical activity for cancer survivors: meta-analysis of randomised controlled trials. BMJ 344:e70-e70. https://doi.org/10.1136/bmj.e70

51. Zdravkovic A, Hasenohrl T, Palma S, Crevenna R (2020) Effects of resistance exercise in prostate cancer patients: a systematic review update as of March 2020. Wien Klin Wochenschr 132:452463. https://doi.org/10.1007/s00508-020-01713-x

52. Campbell KL, Winters-Stone KM, Wiskemann J et al (2019) Exercise guidelines for cancer survivors: consensus statement from international multidisciplinary roundtable. Med Sci Sports Exerc 51:2375-2390. https://doi.org/10.1249/MSS.0000000000002116

53. American College of Sports Medicine (2019) ACSM guidelines for exercise and cancer. https://www.acsm.org/blog-detail/acsmcertified-blog/2019/11/25/acsm-guidelines-exercise-cancer-downl oad. Accessed 6 Dec 2020

54. Cormie P, Atkinson M, Bucci L et al (2018) Clinical Oncology Society of Australia position statement on exercise in cancer care. Med J Aust 209:184-187. https://doi.org/10.5694/mja18.00199

55. Berkel AEM, Bongers BC, Kotte $\mathrm{H}$ et al (2021) Effects of community-based exercise prehabilitation for patients scheduled for colorectal surgery with high risk for postoperative complications: results of a randomized clinical trial. Ann Surg. https://doi.org/10. 1097/SLA.0000000000004702

56. Arends J, Baracos V, Bertz H et al (2017) ESPEN expert group recommendations for action against cancer-related malnutrition. Clin Nutr 36:1187-1196. https://doi.org/10.1016/j.clnu.2017.06. 017

57. Fearon K, Arends J, Baracos V (2013) Understanding the mechanisms and treatment options in cancer cachexia. Nat Rev Clin Oncol 10:90-99. https://doi.org/10.1038/nrclinonc.2012.209

58. Aapro M, Arends J, Bozzetti F et al (2014) Early recognition of malnutrition and cachexia in the cancer patient: a position paper of a European School of Oncology Task Force. Ann Oncol 25:14921499. https://doi.org/10.1093/annonc/mdu085

59. Chasen MR, Feldstain A, Gravelle D et al (2013) An interprofessional palliative care oncology rehabilitation program: effects on function and predictors of program completion. Curr Oncol 20:301-309. https://doi.org/10.3747/co.20.1607

60. Solheim TS, Laird BJA, Balstad TR et al (2018) Cancer cachexia: rationale for the MENAC (Multimodal-Exercise, Nutrition and Anti-inflammatory medication for Cachexia) trial. BMJ Support Palliat Care 8:258-265. https://doi.org/10.1136/bmjsp care-2017-001440

61. Gillis C, Davies SJ, Carli F et al (2021) Current landscape of nutrition within prehabilitation oncology research: a scoping review. Front Nutr. https://doi.org/10.3389/fnut.2021.644723

62. Barberan-Garcia A, Ubré M, Roca J et al (2018) Personalised prehabilitation in high-risk patients undergoing elective major abdominal surgery: a randomized blinded controlled trial. Ann Surg 267:50-56. https://doi.org/10.1097/SLA.0000000000002293

63. Mouch CA, Kenney BC, Lorch S et al (2020) Statewide prehabilitation program and episode payment in Medicare beneficiaries. J Am Coll Surg 230:306-313.e6. https://doi.org/10.1016/j.jamco llsurg.2019.10.014

64. Gillis C, Buhler K, Bresee L et al (2018) Effects of nutritional prehabilitation, with and without exercise, on outcomes of patients who undergo colorectal surgery: a systematic review and metaanalysis. Gastroenterology 155:391-410.e4. https://doi.org/10. 1053/j.gastro.2018.05.012 
65. Gillis C, Fenton TR, Sajobi TT et al (2019) Trimodal prehabilitation for colorectal surgery attenuates post-surgical losses in lean body mass: a pooled analysis of randomized controlled trials. Clin Nutr 38:1053-1060. https://doi.org/10.1016/j.clnu.2018.06.982

66. Tan S, Meng Q, Jiang Y et al (2020) Impact of oral nutritional supplements in post-discharge patients at nutritional risk following colorectal cancer surgery: a randomised clinical trial. Clin Nutr. https://doi.org/10.1016/j.clnu.2020.05.038
67. National Cancer Policy Forum, Board on Health Care Services, Institute of Medicine (2011) Patient-centered cancer treatment planning: improving the quality of oncology care: workshop summary. National Academies Press, Washington, D.C

Publisher's note Springer Nature remains neutral with regard to jurisdictional claims in published maps and institutional affiliations. 